\title{
A transformação dos mecanismos de materialização política das identidades nacionais: o Estado autonômico espanhol e a emergência das autonomias-nação basca e catalã
}

Changing political materialization mechanisms of national identities: the Spanish Autonomic State and the emergence of the Basque and Catalan nation-autonomies

FELIPE VASCONCELOS ROMÃO*

Rev. Bras. Polít. Int. 56 (2): 63-78 [2013]

\section{Introdução}

O nacionalismo tem sido uma das forças dominantes nas políticas nacionais e na política internacional desde o século 19. As unificações de Estados como a Alemanha e a Itália, as guerras mundiais ou um conjunto variado e geograficamente disperso de revoluçôes, que moldaram o sistema internacional tal como o conhecemos, são indelevelmente marcados por fenômenos relacionados com o nacionalismo. No início dos anos 1990, com a conflitualidade gerada pelo desmantelamento das federaçôes soviética e iugoslava, o conceito recupera parte do protagonismo perdido no contexto do discurso ideológico da Guerra Fria.

Por outro lado, o Estado-nação, forma ambicionada pela generalidade dos nacionalistas para materializar as ambições políticas da sua identidade, nunca deixou de desempenhar um papel principal no sistema internacional. No entanto, esse ator evoluiu e as suas transformações internas foram influindo no contexto internacional em que se insere. A nação continua a ser determinante na definição e constituição de um Estado? Os nacionalismos transformaram-se ou têm mantido alguma inflexibilidade face à evolução dos quadros políticos internacional e doméstico? Há novas possibilidades de materialização política das identidades nacionais ou estas continuam a não prescindir do Estado? A pertinência de tentar responder a todas essas questões, entre outras, demonstra a importância da contribuição dos estudos em torno do nacionalismo.

* Felipe Vasconcelos Romão é pesquisador de Pós-Doutorado do Centro de Estudos Sociais da Universidade de Coimbra, Portugal (vasconcelosromao@gmail.com). 
O nacionalismo não pode ser observado como um fenômeno excêntrico ou atípico, que só marca presença em acontecimentos violentos ou em manifestações radicais. As identidades nacionais fazem parte dos Estados democráticos que, na sua esmagadora maioria, continuam a contar com uma base identitária. Quando esta base é plural, ou seja, quando comporta mais do que uma identidade dentro das suas fronteiras, a democracia pode, inclusivamente, fornecer os instrumentos necessários para canalizar os conflitos que decorram da sobreposição de interesses dos vários nacionalismos presentes, como tem sido visível nos casos da Escócia no Reino Unido ou da Catalunha na Espanha.

Este artigo visa a abordar a forma como as identidades nacionais podem se materializar em formas políticas alternativas ao Estado-nação. Na primeira parte, abordamos a problemática de uma perspectiva conceitual. $\mathrm{Na}$ segunda parte, recorrendo ao percurso recente do País Basco e da Catalunha, procuramos identificar como o processo de democratização espanhol permitiu a materialização do que qualificamos como autonomias-nação.

\section{Abordagem conceitual}

\section{Estado-nação tradicional e soberania}

O Estado-nação foi a principal unidade política do sistema internacional nos últimos 200 anos, funcionando o Estado como a estrutura do poder político e a nação como o seu conteúdo. Independentemente do julgamento que possamos fazer em relação ao fato de o Estado-nação ser uma causa ou uma consequência do nacionalismo, deve-se reconhecer que este está no centro da atividade dos sistemas políticos nacionais e internacional nos últimos dois séculos. Para esse protagonismo terão contribuído dois momentos históricos que, embora diferenciados, se complementam como bases desse quadro: a denominada "Paz de Vestefália", em meados do século 17, e o "despertar das nações europeias", a partir do final do século 18 .

João Gomes Cravinho considera que os Tratados de Vestefália, assinados em 1648 com o objetivo de pôr fim à Guerra dos Trinta Anos, simbolizam a "inauguração da modernidade nas relações internacionais", que se materializa numa "nova ordem internacional baseada em entidades territoriais distintas e autónomas" (2002, 60 e 62). Estas não são mais do que os Estados modernos, que são dotados de uma dupla qualidade: "superioridade interna e insubmissão externa", o que consubstancia o princípio da soberania, ao qual está subordinada essa nova ordem (Cravinho 2002, 63). Vestefália fornece-nos, assim, o Estado soberano como ator internacional por excelência. No entanto, os primeiros grandes impulsos a favor da coincidência entre a nação e o Estado só irão ocorrer no final do século seguinte, a partir de 1789, com a Revolução Francesa e com o posterior desenvolvimento do nacionalismo alemão (Berstein e Milza 1997, 154). 
O fato de este modelo de organização permanecer, em linhas gerais, consideravelmente atual não é sinônimo de imobilismo. Apesar de o Estado manter o estatuto de principal ator político, registraram-se algumas mudanças que acabaram por ter consequências para a estrutura do sistema internacional. Julgamos importante assinalar três, relacionadas entre si: a emergência de atores não estatais, como as organizações internacionais, as organizações não governamentais ou os grupos empresariais multinacionais; o dinamismo e a flexibilidade demonstrados pelo conteúdo do princípio da soberania; e a redefinição interna dos próprios Estados, que, nas últimas décadas, começaram a demonstrar um maior grau de heterogeneidade interna, abandonando a imagem monolítica de que pareciam gozar.

\section{Alternativas conceituais à tradicional exigência de soberania}

Para efeitos do que pretendemos tratar neste texto, interessa-nos, sobretudo, a crescente heterogeneidade demonstrada por alguns Estados. A esse propósito, convirá sublinhar que grande parte da teorização e da ação política desenvolvidas em torno do nacionalismo e das aspiraçôes políticas das identidades nacionais assume que o principal corolário das suas ambições é o Estado-nação (Anderson 2006, 7; Gellner 2006, 128-9; Miscevic 2000, 4). Porém, o dinamismo interno revelado pelas realidades intraestatais acabou por pôr em causa a exigência inalienável da soberania plena. Scott L. Greer, no início da obra Nationalism and Self-Government, considera errado pensar nos Estados-nação unificados como unidade política básica, apesar da adequação do seu papel como mito ou como meta a alcançar $(2007,1)$. Esse autor destaca também a importância do ressurgimento daquilo que qualifica como "nacionalismos sem Estado" ("stateless nationalisms") e do desenvolvimento de governos regionais como veículo de representação de nações mais pequenas (2007, 3-4). Na mesma linha, pode ser citado o "nacionalismo liberal" de Yael Tamir (1993) ou o "pequeno nacionalismo" de Mary Kaldor (2004).

$\mathrm{O}$ "nacionalismo liberal" sublinha o fator cultural como potencial agregador de realidades nacionais e não considera que o objetivo político, por excelência, de uma nação seja, necessariamente, o estabelecimento de um Estado independente e soberano. Diferentes naçóes podem acomodar-se num mesmo Estado sem que daí advenha, como consequência automática, um conflito violento. Não obstante, Tamir admite que a perspectiva dominante desde o século 18 assume a nação como única fonte de legitimidade do Estado. Como consequência, cada grupo que se autoidentifica como nação pretende instituir o seu próprio Estado, enquanto os membros de um Estado aspiram constituir-se como nação, não se limitando à neutra denominação de população $(1993,62)$.

Yael Tamir propõe mesmo um modelo alternativo ao do direito à autodeterminação nacional democrático (político): o da "autodeterminação cultural” (1993, 69). Este não conduzirá a uma independência política, mas 
permitirá a uma nação preservar os seus traços identitários, no âmbito de um sistema democrático. Torna-se evidente que essa perspectiva pretende acentuar o fator democracia em detrimento do fator soberania, o que constitui uma forma de preservar a estabilidade do sistema internacional, ao mesmo tempo em que a potencial conflitualidade interna é canalizada para vias de descompressão democráticas.

David Miller também demonstra grande prudência quando equaciona potenciais independências nacionais, o que o leva a defender a necessidade de uma teoria da secessão $(2000,111-113)$. É evidente o receio de Miller em relação às consequências subjacentes à assunção política do princípio de autodeterminação das nações, razão pela qual a sua teoria acaba por não ser muito mais do que a proposta de uma análise casuística de cada situação para, em função de cada realidade concreta, poder ser formulado um julgamento. Esse julgamento poderá determinar a criação de um Estado independente, mas também poderá levar à instituição de uma autonomia local ou de um estado federado $(2000,124)$. $\mathrm{O}$ autor entra assim em ruptura com o conceito de Estado nacionalmente homogêneo, tradicionalmente defendido pelos nacionalistas.

Will Kymlicka (1995) na obra Multicultural Citizenship aborda a questão dos direitos políticos das minorias étnicas e das naçôes minoritárias integradas em Estados independentes. Sendo claramente perceptível a sua opinião contrária ao princípio da autodeterminação nacional, assume também uma posição crítica em relação ao individualismo, procurando apresentar uma opção compatível com o liberalismo, que tenha em conta determinados direitos coletivos. Kymlicka considera que a dimensão nacional (coletiva) é inegável na vida política de um Estado, pelo que a mera aplicação do individualismo, tradicionalmente defendido pelos liberais, pode ser geradora de injustiças.

A enorme vantagem de que gozam os membros da nação majoritária de um Estado reflete-se na possibilidade que têm de influenciar as opçôes políticas governativas (educação e burocracia, por exemplo). Ainda segundo o mesmo autor, a correção dessas situações passa pelo reconhecimento de direitos às minorias, o que permitirá algum reequilíbrio no interior do sistema político em questão (1995, 194-5). Esse reconhecimento acaba por não se materializar em instituições políticas concretas, uma vez que Kymlicka considera o autogoverno (mesmo quando o Estado em que se encontre lhe atribua competências muito limitadas) uma porta aberta para exigências de soberania $(1995,182)$.

\section{Alternativas institucionais ao modelo de Estado-nação tradicional}

Entre as formas de Estado dotadas de uma organização territorial mais adequada à conjugação de diferentes identidades nacionais dentro de uma mesma unidade política soberana, encontramos o Estado federal e o que Jorge Miranda classifica como "Estado unitário regional" (1994, 259). Este, também conhecido 
como Estado autonômico ou Estado das autonomias, teve uma contribuição importante para pôr fim à exclusividade da imagem da nação centralizadora como uma identidade que procura subjugar, por meio do Estado, as suas congêneres periféricas, sem lhes reconhecer quaisquer direitos específicos.

$\mathrm{O}$ Estado contemporâneo já não corresponde à imagem padronizada do modelo jacobino e centralizador que tem nos órgãos de soberania nacionais o único ponto a partir do qual é exercido o poder político. Atualmente, coexistem diversos modelos estatais de organização territorial, podendo o Estado unitário regional ter como grande objetivo a acomodação de aspirações políticas periféricas, por meio do recurso à criação de novos polos de poder, geograficamente não coincidentes com a capital, para os quais são transferidas competências tradicionalmente exercidas pelo governo central. Por intermédio da aplicação dessas formas jurídicoconstitucionais, são criados mecanismos de descompressão que procuram aliviar, pelo menos parcialmente, tensôes identitárias por meio de vias institucionais, o que vai em linha com os teóricos do nacionalismo liberal, quando relativizam o objetivo de independência nacional em favor de processos de autodeterminação cultural e de aprofundamento autonômico ou federal (Tamir 1993, 69; Miller 2000, 124).

O Estado federal que, pelas suas características, poderia ser encarado como a opção mais lógica para os países democráticos com tensões nacionais internas, acaba por não se revelar muito cativante, pelo que nos é dado a observar pela realidade dos diferentes Estado dotados de pluralidade nacional interna. Não é de descartar que haja algum receio em ir muito longe na descentralização formal, o que não prejudica que um Estado unitário regional, na prática, seja tão ou mais descentralizador do que uma federação, em relação às competências que atribui aos níveis infraestatais. É importante assinalar que, nas questôes relativas à soberania, o simbólico ainda tem muito peso. A título de exemplo, podemos observar que três dos sistemas federais mais relevantes - o norte-americano, o brasileiro e o alemão -, não contam com nacionalismos centrífugos com relevância política no seu seio. O sistema federal canadense, que abarca a província do Québec (que conta com um forte movimento nacionalista centrífugo), entre as democracias ocidentais, parece constituir uma rara exceção. Por outro lado, há vários Estados com realidades desse gênero que optam por modelos formalmente unitários, embora descentralizados, como o Reino Unido, a Espanha ou a Itália.

Nesse contexto, a famosa expressão disjuntiva "Independência ou morte", pronunciada pelo imperador Pedro I quando da independência do Brasil, que parecia perfeitamente adaptável a décadas de conflitos secessionistas ou expansionistas, deixa de fazer sentido. $\mathrm{O}$ objetivo final de independência pode agora ser protelado, pelo nacionalismo centrífugo, para um momento mais oportuno, dando lugar a uma grelha muito mais indefinida e complexa de objetivos intermédios que, uma vez cumpridos, poderão, ou não, dar lugar à secessão. Isso leva a uma alteração de estratégia pelo nacionalismo centrípeto, que pode prescindir do discurso musculado e concentrar-se no menos visível conflito pelos objetivos 
intermediários. No fundo, esse é o debate principal, uma vez que, consoante o que aqui se passe, haverá, ou não, margem para evoluir para o debate final: o da independência nacional.

Em seguida, procuraremos identificar a forma como esse quadro pode ser aplicado no caso do sistema político e territorial atualmente em vigor na Espanha.

\section{O caso espanhol}

\section{A democratização política e territorial da Espanha}

A liberalização política iniciada com a morte do ditador Francisco Franco, em 1975, abriu portas à integração da Espanha nas instituições europeias e à redefiniçãoo interna do Estado, que abandonou o centralismo rígido e assumiu parcialmente a diversidade interna. A Constituição de 1978, que fixou o sistema democrático sucessor da ditadura franquista, optou por um modelo de Estado que assenta a soberania numa única nação (art. $2^{\circ} \mathrm{da}$ Constituição). As outras identidades foram classificadas como "nacionalidades", na acepção meramente cultural da palavra, não lhes tendo sido atribuída qualquer soberania formal. O legislador constituinte, fruto dos alinhamentos políticos da época, nem equacionou seriamente a instituição de um Estado federal, sublinhando explicitamente, na nova lei fundamental, o caráter unitário da Espanha.

Porém, os resultados do processo de democratização, ao nível da soberania material, afiguram-se evidentes. O Estado espanhol cedeu competências em duas frentes: no âmbito da integração europeia e no âmbito do processo de descentralização territorial. Nesse caso, as beneficiadas foram as novas comunidades autônomas, instituídas com base na Constituição de $1978 .{ }^{1}$ Surgiram, assim, espaços de compatibilização de identidades que procuraram maximizar o bemestar dos cidadãos por via genérica e estatal e por via mais específica e autonômica.

Em termos gerais, poderíamos considerar que o processo de democratização territorial espanhol acabou por constituir um jogo de soma positiva para as várias partes envolvidas. Madrid, a capital do Estado, ganhou porque, nas últimas décadas, se transformou no grande centro econômico e político do novo Estado democrático, concentrando sedes e representaçōes de grandes empresas nacionais e multinacionais, ao mesmo tempo que mantinha o papel de capital e de sede do poder político estatal. Ganharam as diversas comunidades autônomas que,

1 Stephen D. Krasner, no ensaio Sovereignty: Organized Hypocrisy, considera que o termo soberania pode ser empregado com quatro sentidos diferentes: soberania legal internacional, em referência às práticas de reconhecimento mútuo entre Estados; soberania "vestafaliana", para traduzir a norma de exclusão de atores externos das estruturas de autoridade dos territórios (Estados); soberania doméstica, para se referir à autoridade formal e ao seu exercício efetivo no domínio interno do Estado; e soberania de interdependência, em referência à capacidade das autoridades internas para controlar/regular a passagem de informação, ideias, bens, pessoas capitais pelas fronteiras do Estado (1999, 3-4). À luz dessa segmentação, Krasner considera que os Estados-membros da Uniāo Europeia, por meio do exercício da sua soberania legal internacional, chegaram a acordos para reconhecer estruturas de autoridade externas e, dessa forma, prescindir de parte da sua soberania "vestefaliana" $(1999,4)$. 
em geral, beneficiaram com a descentralização, que permitiu aos novos órgãos regionais de poder que se estabeleceram constituir-se como polos de atração. Também saíram beneficiadas as nacionalidades basca e catalã, as duas principais identidades nacionais centrífugas que integram a Espanha, que passaram a contar com formas políticas (as comunidades autônomas), o que acabou por se revelar muito importante para a sua consolidação e fortalecimento.

Em relação a esse último ponto, André Lecours assume, na obra Basque Nationalism and the Spanish State, a adesão ao institucionalismo e afirma que o papel das instituições políticas é fundamental para o desenvolvimento do que denomina "nacionalismo subestatal". Segundo esse autor, a organização/divisão territorial do poder em estruturas federais ou descentralizadas acarreta um potencial de geração de identidade, ao criar grupos diferenciados por meio da agregação e divisão de pessoas $(2007,16)$. Somos levados a concordar com Lecours, especialmente no que diz respeito à simbiose que se estabelece entre identidades e atores políticos.

São, assim, inegáveis as profundas alterações que o Estado autonômico provocou na Espanha das últimas décadas. O fato de terem sido instituídas comunidades autônomas em todo o território contribuiu para a generalização de uma descentralização acentuada. São facilmente constatáveis os vínculos dessa nova realidade com os casos específicos do País Basco e da Catalunha. A esse propósito, Imanol Zubero considera

que a profunda transformação da organização territorial do Estado impulsionada em Espanha desde 1978 [...] foi na realidade uma tentativa de resposta aos problemas estruturais derivados das exigências de autogovernação dos nacionalismos basco e catalão, e, em menor medida, do nacionalismo galego. (Zubero 2008, 171).

\section{Um sistema assimétrico}

A implantação do Estado autonômico espanhol, em geral, e das comunidades autônomas basca e catalã, em particular, foram processos muito rápidos e que permitiram uma observação, em tempo real, do desenvolvimento e da adaptação de identidades, em linha com as perspectivas modernistas de Gellner (2006) e de Anderson (2006). A grande diferença entre os casos concretos em questão e os quadros traçados por esses teóricos reside no fato de não estarmos a falar da atuação política de um Estado independente ou, sequer, de um estado federado, mas sim dos órgãos políticos de comunidades autônomas que atuam no quadro de um Estado-nação autonômico, que não chega a assumir explicitamente a sua pluralidade interna.

Porém, a não assunção explícita não implica que tenhamos dúvidas em relação à pluralidade nacional espanhola. Essa realidade acarreta um elevado grau de complexidade que se materializa com especial incidência em dois aspetos específicos: 
- Existência de uma identidade centrípeta - espanhola - que, pela sua dimensão e por razôes histórico-políticas de várias ordens, é dominante em termos políticos, culturais e econômicos.

- Existência de duas identidades centrífugas particularmente fortes - a basca e a catalã.

A presença das identidades nacionais basca e catalã são, de resto, indissociáveis de uma das principais características do sistema autonômico espanhol: a assimetria. Esta começou a ganhar forma mesmo antes da aprovação da Constituição de 1978 e foi se aprofundando com o desenvolvimento legal e político do novo regime. Durante o processo de transição democrática, o governo central, liderado por Adolfo Suárez, permitiu e, até certo ponto, incentivou a implantação de instituições "pré-autonômicas" na Catalunha e no País Basco. Estas acabaram por servir de ponte institucional entre os dois regimes. Não obstante, ao não terem sido generalizadas a todo o território espanhol, são uma primeira pedra na materialização assimétrica.

O texto constitucional reconhece as "pré-autonomias" e acolhe-as na primeira e na segunda disposiçôes transitórias. Em concreto, a segunda disposição permite uma via rápida de acesso a competências transferidas pelo Estado central, por parte de territórios com órgãos pré-autonômicos que "no passado tivessem plebiscitado afirmativamente projetos de Estatuto de autonomia" (Constitución Española 1978, 49). Estamos, assim, perante um elemento de diferenciação (territórios que no passado tivessem contado com um estatuto), que, por sua vez, abre portas a um realce da diferença (comunidades com acesso a mais competências no momento da sua instituição): a assimetria formal conduz à assimetria material. Porém, nessa matéria, a Constituição de 1978 não fica por aqui e a primeira disposição adicional reconhece explicitamente o amparo e respeito pelos "direitos históricos dos territórios forais" (Constitución Española 1978, 48). Tendo em conta que esses direitos não abrangem todo o território do Estado, fica introduzido outro elemento de diferenciação, que potencializa a assimetria do sistema.

Já com o regime democrático plenamente instituído e com a Constituição em vigor, na sequência da instabilidade política gerada pelo modelo de aprovação do estatuto de autonomia da Andaluzia, a assinatura do primeiro pacto autonômico, em 1981, consolidará a ideia de dois tipos de comunidades autônomas: as denominadas "históricas" e as de regime comum. O primeiro grupo fica limitado à Catalunha, ao País Basco, à Galícia e à Andaluzia, e o segundo grupo é formado por todas as outras comunidades que, por via desse pacto, deverão seguir um conjunto de regras comuns, como, por exemplo, a eleição dos respetivos parlamentos na mesma data. A ideia que presidiu à celebração desse acordo, assinado entre o governo da Unión de Centro Democrático (UCD) e o Partido Socialista Obrero Español (PSOE), foi a de impor alguma ordem a todo o processo, por meio do preenchimento de lacunas constitucionais, como as ausências de um mapa territorial e de uma distribuição 
clara de competências. Dessa forma, preveniam-se casos semelhantes ao andaluz, passíveis de gerar um processo de reforma territorial anárquico e potencialmente gerador de instabilidade para uma democracia muito recente.

$\mathrm{Na}$ prática, toda esta diferenciação, que tem a sua viga-mestra no fato de a Constituição de 1978 não dividir de forma explícita e impositiva as competências do Estado entre as comunidades autônomas e a administração central (como pode ser verificado pela redação dos artigos 148 e 149), contribuiu para a consolidação de um sistema territorial em que não existe uniformidade entre as autonomias. Recorde-se que o artigo 143 da lei fundamental, que reconhece o direito à autonomia, não obriga a que todo o território esteja organizado dessa forma e que, no limite, assume que se poderia dar o caso de alguma região não pretender usufruir de administração autonômica. Porém, deve ressalvar-se que a assimetria, na Espanha, é sobretudo material. Em termos formais e institucionais, as assimetrias são muito menores, ${ }^{2}$ o que justifica que autores como Roberto Blanco Valdés (2006) considerem o sistema simétrico, em virtude de todo o território ter ficado preenchido com autonomias com características institucionais similares. Obviamente, se só existissem comunidades autônomas numa parte do território do Estado, a assimetria seria mais profunda.

Seja pelas diferenças culturais, que se refletem na existência de línguas próprias em determinadas comunidades, pela forma como se permitiu a algumas autonomias adquirir mais competências em menos tempo ou pelo reconhecimento de direitos históricos que consubstanciam regimes fiscais alternativos ao regime geral, a Espanha caminhou para um modelo não uniformizado. Esse quadro, ao contar com vários elementos que potenciam a sua heterogeneidade desde o momento em que se conformou, com o passar dos anos, tende a acentuar as diferenças entre as várias comunidades autônomas, como pode ser verificado pelos complexos processos de revisão estatutária.

\section{A emergência do País Basco e da Catalunha como autonomias-nação}

Os nacionalismos basco e catalão foram determinantes no enquadramento inicial e na consolidação das respetivas regiōes como comunidades autônomas da "nova” Espanha democrática. O reconhecimento do País Basco e da Catalunha como realidades diferenciadas dentro do todo espanhol, que virá a se materializar na supra mencionada assimetria, fica patente na deferência demonstrada pelas

\footnotetext{
2 Também existem assimetrias formais. As diputaciones forales das três províncias bascas são eleitas por sufrágio direto e universal. O mesmo método é empregue para a eleição dos membros dos cabildos insulares, no arquipélago das Canárias, e dos consejos insulares, no arquipélago das Baleares. Esses órgãos administrativos são equivalentes às deputaçōes. No restante do território vigoram as diputaciones provinciales, exceção feita às comunidades autônomas compostas por uma só província (Astúrias, Cantábria, La Rioja, Madrid, Múrcia e Navarra), que não contam com esse órgão. As deputações provinciais são eleitas de forma indireta, pelos membros dos ayuntamientos (câmaras municipais) dos municípios que compóem a província. No caso de Navarra, província com estatuto foral, o governo autonômico também é denominado deputação foral.
} 
novas autoridades do Estado em relação aos governos basco e catalão no exílio e aos partidos e personalidades nacionalistas que os lideravam. Esse aspeto é especialmente relevante no segundo caso, com a Generalitat catalã no exílio, liderada pelo republicano Josep Tarradellas, a ser reconhecida pelo presidente do governo espanhol, Adolfo Suárez, como base da pré-autonomia por meio do Real Decreto-Ley 41/1977, de 29 de setembro. Francisco José Ferraro García chega mesmo a afirmar que "com as pré-autonomias, o papel dos partidos nacionalistas e regionalistas foi alcançando prerrogativas de representação e de legitimidade muito acima da sua representatividade eleitoral" $(2006,14)$.

Em relação ao País Basco, a situação não é tão escorreita e opta-se por uma estrutura mais confederal, o Consejo General Vasco, instituído pelo Real Decreto-Ley 1/1978, de 4 de janeiro, com o objetivo de conseguir integrar as três províncias bascas e de não fechar portas à possibilidade da incorporação de Navarra numa comunidade basca alargada. O órgão pré-autonômico basco não responde, assim, à mesma lógica de continuidade do seu congênere catalão, o que explica que o governo no exílio permaneça em funções até à instituição dos órgãos definitivos. Não obstante, os nacionalistas bascos participaram ativamente nas estruturas da etapa da pré-autonomia (Corcuera Atienza 2009, 334-5).

\section{Os estatutos autonômicos como constituição das autonomias basca e catalã}

Como consequência natural da diferenciação entre comunidades históricas e comuns, o País Basco e a Catalunha são as primeiras regiões a ver os seus estatutos aprovados (Ley Orgánica 3/1979e Ley Orgánica 4/1979) e a se beneficiar de órgãos autonômicos. Luis Cosculluela Montaner considera que bascos e catalães, pelo caráter pioneiro nessa matéria, acabam por constituir um ponto de referência para as restantes comunidades autônomas, mesmo no caso das instituídas por meio do artigo 143 da Constituição, também classificadas como de "via lenta" $(1996,47)$.

Às comunidades de "via rápida", por força do artigo 151 e da segunda disposição transitória da Constituição, é permitido aceder, inclusivamente, às competências de matéria concorrencial com o Estado central, vedadas por um período de cinco anos às restantes comunidades. Em relação à organização institucional, a Constituição também define regras incontornáveis para as comunidades cujo estatuto seja elaborado e aprovado com base no artigo 151 . É o caso do artigo 152, que obriga ao estabelecimento de uma assembleia legislativa eleita proporcionalmente por sufrágio universal, a partir da qual deverá ser formado um governo, o que acaba por mimetizar a organicidade dos poderes legislativo e executivo dos sistemas parlamentares de Estados soberanos. Os estatutos de autonomia basco e catalão acabam, assim, com as devidas adaptações, por exercer as funções de constituição das respectivas autonomias, definindo as competências que estão a cargo dessas unidades territoriais e a forma como se organiza o poder político. 
Ao observar o texto dos estatutos basco e catalão, torna-se óbvia a presença do elemento identitário, bem como da tentativa de estabelecer uma relação entre a identidade e a estrutura política que se institui, apesar da presença de representantes dos partidos ativamente adeptos do Estado-nação espanhol no processo de elaboração dos projetos estatutários. Não estamos, em definitivo, perante a instituição de uma região administrativa meramente burocrática, mas sim de algo com vínculos que vão além do elemento político ou jurídico. A porta que o artigo $2^{\circ}$ da Constituição de 1978 abriu, ao reconhecer o direito à autonomia das "nacionalidades", é aproveitada para a maior aproximação legalmente possível a um Estado-nação constitucionalmente impossível.

O primeiro passo que os negociadores e legisladores responsáveis pela redação dos estatutos parecem ter querido dar foi o da delimitação do próprio espaço político em relação ao Estado. Essa tarefa não foi fácil, tendo em conta dois fatores: o caráter aberto da Constituição em relação à forma concreta e aos conteúdos da organização territorial e a escassez de modelos prévios. Os únicos referentes na história constitucional espanhola, até 1978, eram os estatutos autonômicos catalão, basco e galego, redigidos e sufragados durante a Segunda República, e que, com exceção do catalão, não chegaram a vigorar num período de normalidade democrática (no caso da Galícia, nunca chega a entrar em vigor). Se a Constituição de 1978 não é fechada em relação ao modelo autonômico, o mesmo já não se pode dizer em matéria de identidade nacional, uma vez que o artigo $2^{\circ}$, como já foi referido, não permite contornar a exclusividade da nação espanhola, o que, por sua vez, limita as autonomias com base identitária em termos de autodefinição.

O preâmbulo do estatuto catalão de 1979 assume textualmente a "identidade coletiva da Catalunha" e faz um enaltecimento das suas instituições políticas (Generalitat) como expoente de uma defesa dos direitos fundamentais e liberdades públicas (Ley Orgánica 3/1979). No último parágrafo, é feita referência à inalienabilidade do autogoverno da Catalunha. $\mathrm{O} 1^{\circ}$ artigo do estatuto vai no mesmo sentido, reafirmando a condição de nacionalidade, à luz do previsto na Constituição. O estatuto do País Basco, cujo texto nunca foi revisto, no $1^{\circ}$ artigo, também assume a condição de nacionalidade, mas pode constatar-se uma maior distância em relação à Espanha, identificada como o meio necessário para atingir um fim: "O Povo Basco ou Euskal Herria, como expressão da sua nacionalidade, e para aceder ao seu autogoverno, constitui-se em Comunidade Autônoma dentro do Estado espanhol" (Ley Orgánica 4/1979).

A própria terminologia empregada ao longo dos dois textos legais para aludir à Espanha tem subjacente uma conotação política, com os bascos a recorrer exclusivamente à expressão formal "Estado espanhol". Esta parece ser uma forma encontrada para esvaziar o caráter identitário da Espanha, no mesmo estatuto que impulsiona a identidade basca, depois de anos de subjugação à ditadura franquista. Pelo contrário, os catalães não recorrem a nenhuma fórmula evasiva e, mesmo depois da reforma de 2006, empregam com normalidade o termo "Espanha". Em 
aplicação do ponto 2 do artigo $3^{\circ}$ e do artigo $4^{\circ}$ da Constituição, os estatutos de autonomia basco e catalão também assumem uma língua própria e uma bandeira.

\section{Competências das autonomias basca e catalã}

A atribuição de competências às comunidades autônomas foi essencial para a sua consolidação, principalmente se levar-se em conta a ausência de enraizamento histórico das novas estruturas territoriais. Dessa forma, os cidadãos espanhóis conseguiram materializar algo que lhes era totalmente desconhecido, dado o elevado grau de centralização do regime precedente. No caso do País Basco e da Catalunha, enquanto autonomias da denominada "via rápida", a recepção inicial de funções foi mais alargada, o que lhes permitiu atuar em áreas como a saúde e a educação desde o princípio da década de 1980. Já a maior parte das comunidades autônomas do regime comum só recebem essas competências nos anos 1990 (GilRuiz e Iglesias Quintana 2007, 197).

Para bascos e catalães, a questão das competências relativas à educação, à língua e à cultura são particularmente relevantes, em função do papel que essas áreas desempenham enquanto elementos caracterizadores e definidores das respectivas identidades. $\mathrm{O}$ artigo $3^{\circ}$ da Constituição espanhola, no $1^{\circ}$ ponto, estabelece o castelhano como língua oficial do Estado. Porém, no $2^{\circ}$ ponto, abre espaço para que o que denomina como "as outras línguas espanholas" também sejam oficiais em determinadas comunidades autônomas, remetendo essa definição para os respectivos estatutos (Constitución Española 1978, 7). ${ }^{3}$ Essa cooficialização é recolhida pelos dois estatutos autonômicos, que qualificam as respectivas línguas como "próprias" (artigo $3^{\circ}$ do estatuto cataláo de 1979 e artigo $6^{\circ}$ do estatuto basco) e, dentro do constitucionalmente permitido, procuram privilegiá-las em relação ao espanhol (Ley Orgánica 3/1979 e Ley Orgánica 4/1979). Caberá, depois, às leis linguísticas, conjugadas com as leis educacionais, desenvolver as ações necessárias para compensar as quatro décadas de interdiçõoes.

As especificidades do País Basco e da Catalunha não se limitam aos aspectos culturais e simbólicos e também se afirmam no campo das denominadas competências de soberania. Uma das primeiras funçōes que o Estado moderno assumiu, mesmo antes do liberalismo, foi a segurança interna, razão pela qual Jorge Miranda denomina o modelo absolutista como "Estado de polícia" (1990, 78). As forças policiais eram uma das formas que os governantes tinham para assegurar a manutenção do seu poder e a cobrança coerciva de impostos. Essa função permanece nos modelos liberal e social e a sua importância fica patente nas palavras de Max

3 A Constituição espanhola, no artigo $3^{\circ}$, no que denominamos como uma tomada de posição política, denomina a língua dominante no Estado como castelhano e considera que as outras línguas (subentende-se que serão as línguas regionalmente circunscritas) também são espanholas (Constitución Española 1978, 7). Ao longo deste trabalho, empregamos o termo sinônimo "espanhol" para denominar o castelhano, em conformidade com a terminologia empregada pela Real Academia Española. 
Weber, quando este se refere ao "monopólio da violência física legítima", como uma das características centrais do Estado (2005, 64). Quando um Estado cede uma parte desse poder a uma unidade territorial descentralizada, está também a ceder um dos seus símbolos mais relevantes.

$\mathrm{Na}$ Espanha, essa cedência não foi levada a cabo de forma explícita. Regra geral, com a Constituição de 1978, o domínio da segurança pública permaneceu no Estado central. No entanto, à semelhança de outros aspectos previstos no artigo 149, no mesmo ponto em que é estabelecida a competência também é estabelecida a exceção, ficando aberta a possibilidade de criação de polícias pelas comunidades autônomas, em função do que ficar previsto nos respectivos estatutos. Em virtude da sua condição de autonomias de "via rápida”, o País Basco e a Catalunha incluem nos seus estatutos autonômicos essa questão (artigo 13 do estatuto da Catalunha de 1979 e artigo 17 do estatuto do País Basco), tendo sido as duas primeiras comunidades a avançar para a criação de forças policiais próprias, integrais e totalmente independentes dos corpos do Estado espanhol. A Ley 19/1983, do parlamento catalão, instituiu os Mozos de Esquadra. A formação da polícia autonômica do País Basco não é tão liminar, em função da complexa organização precedente, com corpos de polícia diferenciados por província foral. A sua unificação formal, por via da Ley 4/1992, do parlamento basco, confirma a instituição da Ertzaintza, que, a partir de 1995, substituiu as forças policiais do Estado na esmagadora maioria das funçóes que desempenham no País Basco (Ertzaintza 2012).

Também nesse caso, as instituições autonômicas do País Basco e da Catalunha demonstraram vontade de aprofundar as suas especificidades em relação ao resto da Espanha, criando estruturas e assumindo funções com uma celeridade considerável, o que acentuou o elemento diferencial. Especialmente relevante é o fato de estarmos perante competências que podem ser consideradas, numa acepção mais tradicional, do domínio da soberania do Estado. Em termos concretos, são criadas estruturas armadas, sob a dependência das administraçóes autonômicas e sem qualquer dever de obediência ao poder executivo do Estado central.

\section{Conclusão}

A instituição do Estado autonômico espanhol não passou pela mera regionalização administrativa ou por uma descentralização simétrica. $\mathrm{Na}$ Espanha política que sai da Constituição de 1978, reconhece-se a existência de realidades identitárias alternativas e estas, por meio dos seus nacionalismos centrífugos, respondem ao desafio colocado pelo novo poder e pelo nacionalismo centrípeto espanhol. Contendo aspiraçôes maximalistas, por intermédio das comunidades autônomas que lhes são concedidas, lançam-se na própria materialização política, recuperando e desenvolvendo línguas e culturas próprias e almejando maiores níveis de autonomia. 
A noção de identidade já existia previamente nos dois casos, como o confirma a incorporação do conceito de "nacionalidades" na Constituição de 1978, com o apoio de parte da própria direita espanhola pós-franquista. A lei fundamental também abriu portas ao desenvolvimento do sistema autonômico e à instituição de atores que dão forma política a essas identidades coletivas e que fomentam o seu desenvolvimento e a sua evolução. Constrói-se, assim, uma ligação entre a identidade nacional e uma entidade política, que é aceita e incorporada pelas suas cidadanias.

A Catalunha e o País Basco distinguem-se, hoje, do Estado espanhol, apesar de o integrarem. Evidentemente, a soberania formal, na acepção mais tradicional, não se materializou e nenhuma das duas regiōes é reconhecida como Estado independente ou tentou, até hoje, declarar a independência. Porém, de forma gradual e por meio das instituiçôes políticas e das competências que estão à sua disposição, encontraram um terreno de afirmação em que o caráter identitário é iniludível. Podemos afirmar, sem grande margem para dúvida, que sem uma identidade nacional definida as comunidades autônomas do País Basco e da Catalunha não teriam se configurado tal como se configuraram, o que nos leva a classificá-las como autonomias-nação, dotadas de traços definidos de soberania material, mas longe de uma soberania formal.

\section{Referências bibliográficas}

\section{Livros, capítulos e artigos}

ANDERSON, Benedict (2006) Imagined Communities. Londres: Verso.

BERSTEIN, Serge; MILZA, Pierre (1997) História do século XIX. Mem Martins: Publicaçōes Europa-América.

BLANCO VALDÉS, Roberto L. (2006) "La revolución territorial española: Estado y sociedad” in Ferraro García, Francisco José (ed.) Un balance del Estado de las Autonomías. Almería: Fundación Cajamar, 109-126.

CORCUERA ATIENZA (2009) "El momento constituyente y la elaboración del estatuto de Guernica (1975-1979)" in Castells, Luis; Cajal, Artuto (eds.) La autonomia vasca en la España contemporénea (1808-2008). Madrid: Marcial Pons, 321-343.

COSCULLUELA MONTANER, Luis (1996) «Los estatutos de autonomia y los pactos autonómicos». Revista de Estudios Regionales, 44, 47-68.

CRAVINHO, João Gomes (2002) Visões do Mundo: as Relações Internacionais e o mundo contemporâneo. Lisboa: Imprensa das Ciências Sociais.

FERRARO GARCÍA, Francisco José (2006) "El estado abierto del estado de las autonomías" in idem (ed.) Un balance del Estado de las Autonomías. Almería: Fundación Cajamar, 11-35.

GELLNER, Ernest (2006) Nations and Nationalism. Ithaca: Cornell University Press.

GIL-RUIZ, Carmen Luisa; IGLESIAS QUINTANA, Jaime (2007) «El gasto público en España en un contexto descentralizado» Presupuesto y Gasto Público, 47, 185-206. 
GREER, Scott L. (2007) Nationalism and Self-Government. Albany: State University of New York Press.

KALDOR, Mary (2004) «Nationalism and Globalisation». Nations and Nationalism. 10(1/2), $161-177$.

KRASNER, Stephen D. (1999) Sovereignty: Organized Hypocrisy. Princeton: Princeton University Press.

KYMLICKA, Will (1995) Multicultural Citizenship. Oxford: Oxford University Press.

LECOURS, André (2007) Basque Nationalism and the Spanish State. Reno: University of Nevada Press.

MILLER, David (2000) Citizenship and National Identity. Londres: Polity Press.

MIRANDA, Jorge (1990) Manual de Direito Constitucional - Tomo I. Coimbra: Coimbra Editora.

MIRANDA, Jorge (1994) Manual de Direito Constitucional-Tomo III. Coimbra: Coimbra Editora.

MISCEVIC, Nenad (2000) «Introduction: The (Im-)morality of Nationalism» in idem (ed.) Nationalism and Ethnic Conflict. Chicago: Open Court, 1-21.

TAMIR, Yael (1993) Liberal Nationalism. Princeton: Princeton University Press.

WEBER, Max (2005) Três tipos de poder e outros escritos. Lisboa: Tribuna da História.

ZUBERO, Imanol (2008) "Viejos y nuevos nacionalismos: España como problema de acción coletiva" in Pérez-Díaz, Victor (ed.) Modernidad, crisis y globalización: problemas de politica y cultura. Almería: Fundación Cajamar.

\section{Legislação}

Constitución Española (1978) Boletín Oficial del Estado, http://www.boe.es/legislacion/enlaces/ documentos/ConstitucionCASTELLANO.pdf [1 de julho de 2012].

Ley 19/1983, de 14 de julio. Diari Oficial de la Generalitat de Catalunya, 347. Parlament de Catalunya. Barcelona.

Ley 4/1992, de 17 de julio. Boletin Oficial del País Vasco, 155/1992. Parlamento Vasco. Victoria.

Ley Orgánica 3/1979, de 18 de diciembre. Boletín Oficial del Estado, 306/1979. Cortes Generales. Madrid.

Ley Orgánica 4/1979, de 18 de diciembre. Boletín Oficial del Estado, 306/1979. Cortes Generales. Madrid.

Real Decreto-Ley 41/1977, de 29 de septiembre. Boletín Oficial del Estado, 238/1977. Consejo de Ministros. Madrid.

Real Decreto-Ley 1/1978, de 4 de enero. Boletín Oficial del Estado, 5/1978. Consejo de Ministros. Madrid.

\section{Sites}

Ertzaintza (2012) http://www.ertzaintza.net/public/wps/portal/ertzaintza [30 de março de 2012].

Recebido em 17 de abril de 2013 Aprovado em 2 de julho de 2013 


\section{Resumo}

Este artigo visa a abordar a forma como duas identidades nacionais concretas, a basca e a catalã, potencializadas pelos respectivos nacionalismos e pelo processo de democratização espanhol, conseguiram materializar-se política e legalmente naquilo que qualificamos como autonomias-nação. Para chegar à análise deste estudo de caso, começa por percorrer o papel do Estado-nação e a relação entre os conceitos de Estado e nação. Destaca de forma especial a emergência de novas unidades políticas, que o autor denomina autonomias-nação, que constituem um autêntico desafio ao conceito tradicional de soberania.

Palavras-chave: Catalunha; Estado autonômico espanhol; nacionalismo centrífugo; País Basco; soberania.

\section{Abstract}

This article aims to address how two specific national identities-Basque and Catalan-, enhanced by their nationalisms and by the Spanish democratization process, were able to materialize politically and legally in what is qualified as nation-autonomies. To analyze this case study we start covering the role of the nation-State and the relationship between the concepts of State and nation. It specially highlights the emergence of new political units, which the author classifies as nation-autonomies, which constitute a real challenge to the traditional concept of sovereignty, focusing the Spanish case.

Keywords: Catalonia; Spanish autonomous State; centrifugal nationalism; Basque Country; sovereignty. 